Fecha de recepción: septiembre 2019 Fecha de aceptación: noviembre 2019 Versión final: febrero 2020

\section{La influencia del ciberespacio como dinamizador del entorno áulico}

Fernando Luis Rolando ${ }^{(1)}$

\begin{abstract}
Resumen: En tiempos en donde la disolución de los límites entre aquello que se ha denominado "realidad" y la influencia de la virtualidad en la construcción de la misma, este trabajo explorara las delimitaciones, las zonas intangibles que desde el ciberespacio permiten potenciar el desarrollo de la imaginación humana, abordando la problemática acerca de cómo los entornos virtuales e inmersivos pueden contribuir a nivel perceptivo al desarrollo de los alumnos dentro de un ámbito convencional. El planteo analizará las limitaciones de las formas de enseñanza dentro de un aula y reflexionara acerca del tratamiento de la noción espacial, contribuyendo a desarrollar la visión de ecosistema digital, que he venido investigando hace tiempo, intentando abrir una ventana interactiva e interdisciplinaria, que construya una avenida de ida y vuelta desde el ciberespacio hacia el entorno áulico, para expandir la forma en que accedemos al conocimiento y abrirnos a un universo de posibilidades creativas e innovadoras.
\end{abstract}

Palabras clave: ciberespacio - percepción - interacción - imaginación - aula - ecosistema - creatividad - innovación.

[Resúmenes en inglés y portugués en la página 200]

(1) Fernando Luis Rolando. Arquitecto (UB). Asistente Diseño (UB). Graduado en Artes Visuales (UNA). Especialización en Planeamiento (UB). Profesor, Miembro Fundador Consejo Asesor Académico y del Comité publicaciones (UP). Vice Director Académico y Postgrados Link Design Consultancy (UA Londres). Trabaja desde 1981 en la fusión de campos digitales. Representó a Argentina en la Expo Sevilla 92 (España). Premio Creatividad Fotografía Digital (Parlamento Mercosur). Reconocimiento Académico por su labor en Multimedia \& Diseño de Imagen y Sonido (UP). Senior Examiner International ArtDesign (Gales). Publica desde 1991 ensayos sobre creatividad, hiperrealidad, arte digital, publicidad interactiva y redes sociales apoyando el uso de sistemas libres y plataformas de difusión gratuitas alrededor del mundo y desarrolla profesionalmente proyectos de realidad virtual y entornos digitales expandidos a nivel internacional.

Agradecimientos: Quiero agradecer a Ivan Sutherland, William Gibson, Morton Heilig, Horacio Reggini, Matías Severino y Gianluca Bertín Rolando, sin cuya inspiración estas líneas no hubiesen sido posibles. 


\section{Antecedentes del ciberespacio y su influencia sobre el mundo real}

Los primeros proyectos vinculados a la relación entre el ciberespacio y su influencia sobre el mundo real tienen que ver con el Sensorama creado en los años 50, por Morton Heilig. Este consistía en un aparato multisensorial que incluía una película pregrabada en color y sonido stereo de tipo Binaural y vibraciones en los asientos, siendo un primer acercamiento a la idea de ingresar dentro de un mundo virtual, aunque no tenía una concepción interactiva como para conectar este con los observadores, ya que recién en el año 1965 apareció la solución definitiva al crearse los postulados acerca de la realidad virtual a partir de las ideas de Ivan Sutherland, construyendo un simulador que incorporaba un sistema de retroalimentación incorporándose gráficos interactivos que eran controlados desde el movimiento de un casco que se colocaba en la cabeza del usuario y de un guante especial. En los años 70 se produjeron los primeros trabajos con retroalimentación al crearse un dispositivo denominado Grope, que permitió trabajar con las primeras nociones de interactividad vinculadas al ciberespacio, siendo esto, sumado al desarrollo del Videoplace en 1975 lo que consiguió generar un entorno conceptual sin existencia, es decir la idea de poder simular un espacio que no tenga existencia o correlación con los parámetros del mundo físico, usando en ese caso, un sistema de siluetas capturadas por diferentes cámaras que se iban reproduciendo sobre varias pantallas. Estos dispositivos sentaron las bases de la retroalimentación, aunque de un modo bastante primitivo, ya que recién en los años 80 los primeros simuladores de vuelo que usaba la fuerza aérea norteamericana como el VCASS y el VIVED construyeron modelos de simulación que integraban los sistemas estereoscópicos por primera vez generando una mayor inmersividad.

Una variante que se creó después, en la década del 80, fue el modelo llamado BOOM que consistía en una caja que incorporaba en su interior dos monitores CRT y que utilizaba una serie de orificios, a través de los cuales miraba el observador, para simular en su mente la idea inmersiva, respecto de estar dentro de un mundo virtual. Esto genero un modelo preliminar de arquitectura tridimensional donde la gente podía recorrer esos sistemas a través de artefactos ópticos y diferentes motores gráficos.

A comienzos de la década del 90, el sistema llamado CAVE permitió construir una simulación en las paredes de una habitación a partir de diagramar el modelado de una caverna usando imágenes estereoscópicas combinadas con los planos de las paredes que se articulaban en los ejes $\mathrm{x}, \mathrm{y}, \mathrm{z}$, más un deslizador donde la gente caminaba y dentro de esa simulación parecía que las paredes se movían. Todo esto fue el comienzo de la masividad del mundo virtual por medio de diferentes artefactos que el ser humano iba creando y los primeros indicios de tratar de plantear la idea de construir, modelizar y diseñar objetos que aparecieran en el espacio virtual afectando el modo de ser percibidos en el mundo real.

En los años 90 la clave estuvo en cómo se expandió la realidad virtual y como estas empresas se fueron desarrollando cada vez más usando al comienzo cascos de gran tamaño para ingresar al ciberespacio, habiendo una gran diferencia, en ese entonces, entre lo veíamos en el mundo tridimensional convencional y su relación con el espacio-tiempo, aunque esto era suficiente para engañar al cerebro por unos instantes, generando la sensación de poder estar y recorrer esos espacios virtuales e incorporarse dentro de ellos. 


\section{Las diferentes formas de interacción en el mundo virtual}

En este punto es interesante plantear que existen diferentes maneras de interactuar dentro de los espacios virtuales expresadas básicamente a través de la forma en que nos relacionamos con el ciberespacio. Uno de los términos más utilizados es hablar de la "experiencia sintética" que indica que la conexión con el mundo virtual es artificial y tienen que ver en la manera en que como nos "ilusionamos" dentro de ese espacio porque queremos participar dentro de ese ambiente que está basado en la construcción de mundos estereoscópicos a los cuales se accede por medio del casco virtual, incorporándole en sus modelos más avanzados un sistema de seguimiento de las manos y una serie de sensores para virtualizar los cuerpos a través de un traje especial. Estas experiencias se ven completadas con el sonido binaural, que es el que permitió lograr una sensación realmente inmersiva a nivel sonoro, siendo mejorada en la actualidad con la incorporación del sonido ambisónico que permite generar un espacio envolvente en $360^{\circ}$ situando en el centro al observador.

\section{La experiencia multisensorial}

La realidad virtual tiende a crear entornos inmersivos, interactivos y multisensoriales.

En la realidad virtual proyectada de forma externa, que forma parte de la propuesta de este texto, nos moveríamos en 3 dimensiones, en tiempo real, con al menos 6 grados de libertad, intentando ir más allá de esta especie de "clonación" de la realidad física ya que la propuesta de crear modelos basados en proyecciones y pantallas, situaría a los observadores por fuera de estos entornos virtuales que fueron creados por los dispositivos de épocas anteriores, pudiendo ingresar a ellos, pero también participar en los mismos desde zonas externas, visualizando todo lo que esta ocurriendo, sin la necesidad de un casco o un objeto que sirva de intermediación entre los observadores y el mundo sintético.

\section{Las ventajas de la telepresencia en el ciberespacio}

Otro aspecto muy ventajoso de la propuesta que se hace en este escrito, es la relación entre la telepresencia y el ciberespacio, dado que, nosotros tendríamos la posibilidad de generar ambientes reales simulados a distancia remota, para interactuar a través de las proyecciones con creadores, especialistas, diseñadores y profesores de otras partes del mundo.

Esto generaría, un incremento en la calidad de la retroalimentación sensorial y potenciaría los contenidos académicos dado que estaríamos construyendo espacios áulicos dinamizados, sin la necesidad de las barreras físicas. Ya en la década del 80, William Gibson hablo del termino del ciberespacio y como este se podía asociar con la telaraña mundial de información asociada a la idea de red neuronal. 


\section{Los hipervínculos y la atemporalidad espacial}

Un aspecto central es que esta interacción con Internet que se propone, crearía hipervínculos, estos hipervínculos generarían nodos, estos nodos podrían formar mapas de ideas dinámicos que amplificarían el conocimiento, y en especial, todas estas experiencias podrían quedar grabadas dentro del ciberespacio sirviendo de aprendizaje remoto de forma atemporal y aespacial.

Este tipo de aprendizaje, es atemporal porque el acceso a la información está allí, puede ser accedida en cualquier momento. También es aespacial porque no requiere de un espacio físico concreto, sino que lo generado en el ámbito proyectado de la universidad y se puede replicar en forma simultánea en diferentes espacios al rededor del mundo.

Otro aspecto importante es considerar que este tipo de espacio áulico incluye un sistema asincrónico, es decir que no requiere que estén al mismo tiempo todos los actores involucrados en el proceso de impartir conocimiento, dado que por ejemplo, puede haber profesores que generen una entrevista, esta entrevista contiene al final, supongamos, un cuestionario, este cuestionario puede ser respondido de manera sincrónica o asincrónica en el espacio virtual desde los celulares, y el profesor puede revisar estas respuestas y formular nuevos planteos sobre el tema investigado generando un feedback que se puede expandir con el aporte de una red de investigadores que se sumen a resolver el problema planteado. Una de las cosas interesantes, también es pensar que estos elementos partieron de las primeras ideas que tenía Wheatstone con su diseño esteroscópico en 1836, cuando generaba patrones de imágenes a partir de dos fotografías, construyendo los primeros visores de imágenes estereoscópicamente. Un sistema similar fue el VIEW-MASTER en 1939, que permitía la doble visualización simultánea que daba sensación de profundidad a los objetos. En la actualidad, tenemos sistemas como el Oculus Rift, HTC Vive y otros que permiten inmersionar en la realidad virtual. Contamos también con los aportes de Clay Bavor del equipo de Realidad Virtual de Google, las gafas creadas por esa empresa y otros dispositivos que permiten amplificar nuestra visión a partir de la realidad aumentada, y todos estos confluyen en el modo en el que podemos poner afuera de nuestra mente las ideas y relacionar estas tecnologías a través de sistemas de proyecciones en el espacio físico por medio del Mapping.

\section{El Mapping y la desmaterialización de la realidad}

El Mapping es una técnica de proyección virtual que permite desmaterializar los elementos de la realidad transformándolos en luz, y recomponerla luego en otras formas. Incluso aquellas que no podrían construirse en el mundo real, por ejemplo, no podríamos hacer que en el mundo real los objetos flotasen. Sin embargo, dentro de una clase de proyección virtualizada, podríamos hacer no solo que los objetos flotasen, sino analizar modelos diseñados desde diferentes ángulos, movernos alrededor de ellos y opinar acerca de cómo podemos generar diferentes variantes de un producto, en tiempo real con nuestros alumnos interactuando con otros profesores a distancia. 


\section{La relación entre las aulas convencionales y el espacio áulico dinamizado}

Cabe aclarar, que estos sistemas de ningún modo reemplazan las aulas convencionales, que seguirán existiendo, pero nos permitirían crear zonas nuevas, llamadas "ecosistemas digitales", donde el conocimiento se amplificaría, donde podemos unir piezas gráficas, elementos tri-dimensionales, imágenes animadas, sonidos y proyecciones de luz, entre otros, construyendo lo que llamamos un espacio vivencial.

El espacio vivencial, es aquel determinado por experiencias sensorias en donde los sentidos pueden verse amplificados debido a los estímulos lumínicos que se pueden recibir mediante diferentes tipos de proyecciones. En efecto, es posible no solamente modificar el espacio a partir de, por ejemplo, un aula que tiene una estructura cubica convencional, pudiendo transformarla a través del fenómeno óptico de las proyecciones, en formas piramidales, estructuras de dodecaedros, hexaedros, octaedros, esféricas, y múltiples formas poliédricas combinadas que no requieren de un costo o inversión económica alguna, sino simplemente del número de proyectores que incidan sobre el espacio, algo que actualmente la universidad no utiliza ya que ha migrado de los proyectores que se usaban en las aulas a un sistema de televisores led, estando muchos de estos proyectores, aún con posibilidades de ser utilizados aplicándolos a estas nuevas funciones de generar un espacio áulico dinamizado virtualmente.

\section{La función perceptiva del espacio y su influencia en la creación de contenidos}

Estas formas espaciales, al ser modificadas, alteran la función perceptiva del espacio, logrando que los estudiantes reciban una mayor cantidad de contenido desde muchas direcciones posibles, pudiendo interactuar con ellas, de manera tal de conseguir que sus mentes y el desarrollo de la imaginación sean estimuladas por la información simultanea recibida. Esta información puede dividirse en diferentes canales. Podemos contar con un canal en donde tengamos un debate de un tema relacionado con el diseño y la morfología, y del otro lado, en el plano virtual, un especialista que hable acerca de la topología, y su influencia en la estructuración de la forma. Así, los estudiantes podrían participar simultáneamente en estos canales, se podrían dividir en grupos, e interactuar desde sus smartphones alternando la información que reciben con la que investigan, transformando el espacio del aula en una área de investigación continua, en donde por ejemplo, se modelizaria en tiempo real, mientras se lo analiza, el proceso de diseño de un producto industrial, de indumentaria o gráfico.

\section{Las ventajas de dinamizar el espacio áulico en los diferentes campos del diseño}

En el campo audiovisual, las capacidades expansivas de este tipo de aulas son mayores, dado que se suma el componente cinético propio del cine y el video, a la interacción es- 
pecifica de los nuevos medios, como el cine en realidad virtual, la aplicación de realidad aumentada, y la generación de estructuras de nuevos tipos de videojuegos, pudiendo entender en uno de los planos de información, como actúa en otra etapa diferente. Por ejemplo, la programación de un juego, y simultáneamente, en otras pantallas, viendo como esta afecta a la simulación de ese juego, generando modificaciones en tiempo real, y viendo como estas afectan al desarrollo del prototipo.

En el caso de una experiencia de guión audiovisual interactivo, se podrían construir personajes que interactúen en diferentes escenas, generando muchas variantes posibles de las mismas, y creando su correlato inmersivo en $360^{\circ}$, viendo un espacio esférico proyectado, como si fuese un sistema como el que existe en La Villette, en Francia, pero en un nivel mas alto en donde la pantalla de proyección es todo el espacio, de modo simultaneo, y los espectadores, actores, o publico pueden participar interactuando con el mismo.

En el área sonora, las proyecciones del Mapping, pueden incluir elementos asociados a la estructura de las partituras, por ejemplo: Podríamos escribir a través de una síntesis MIDI, los sonidos que se van a ejecutar, guardarlos en un banco de información, y simultáneamente, estos estarían proyectando, para que todos los estudiantes de diseño imagen y sonido, puedan comprender acerca de cómo funciona internamente este proceso. En el área teatral, tenemos por ejemplo, el concepto desarrollado en "Skull Mapping", una pieza visual donde los elementos incluidos en la obra teatral se vinculaban a lo que ocurría en la escenografía, interactuando virtualmente los personajes, con las pantallas. También es posible representar las zonas acústicas de la música en tiempo real, a través de las expresiones visuales, como se ha visto en la obra "The Macula", en donde el concierto se vinculaba a las proyecciones de Mapping dentro de una gran escenografía virtual.

Además sería posible para el área de diseño e interiores, renderizar un espacio arquitectónico y recorrerlo. Esto serviría de un potente amplificador de contenidos para la carrera, ya que no solo sería posible plantearse un análisis del diseño de interiores desde el punto de vista de la construcción de planos y maquetas, sino además modelizarlo dentro de un espacio virtual generando proyecciones como se a dado en obras como "Tokyo City Symphony", en donde las maquetas de la ciudad de Tokyo son parte de la construcción de un mundo que solamente existe en el ciberespacio pero que se conecta con los observadores.

\section{Conclusiones}

Vemos como la influencia del ciberespacio como dinamizador del entorno áulico puede traer grandes ventajas. En la generación de nuevos contenidos académicos, el aspecto perceptivo, es el otro elemento fundamental del desarrollo de aulas dinámicas, dado que la relación con los espectadores, la interactividad, y la posibilidad que tienen los docentes de generar nuevos contenidos, se vuelve expansiva, en un entorno de trabajo en donde los alumnos además usan sus smartphones para poder grabar e interactuar con esta plataforma, y volcarlo a la nube.

Acerca de la percepción, en el año 2005 en el texto "La resignificación del espacio en la era de la virtualidad", se plantearon las distintas etapas evolutivas acerca del modo en 
el que a sido representado el espacio, que es el medio fundamental del diseño, a través del tiempo, explorando aspectos como cual fue la relación entre forma y contenido, que planteo tenían a través del tiempo las distintas concepciones del espacio, y como estas cambiaban en diferentes dimensiones a medida que esta visión iba evolucionando, y cuál era la relación entre el sonido y las posiciones espaciales, mencionando que existían patrones pre-adquiridos que se iban superando a partir de los avances en cada época, para llegar a la conclusión respecto que en la época actual, vivimos en una era de no-linealidad e interacción a nivel espacial entre el ciberespacio y el mundo físico, con todo lo que esto implica para los seres humanos.

En ese sentido, en aquel análisis, se llegaba a la conclusión que "la realidad es una frecuencia”. Hoy, visto desde el siglo XXI, ya ingresados en el año 2019, podemos afirmar que la realidad no es solo una frecuencia, sino que además podemos avanzar, en la reconstrucción, en la generación de otras realidades, que pueden servir para la modelización de nuevos prototipos de diseño, nunca antes realizados a través de las proyecciones en los espacios dinámicos áulicos que podemos construir hoy.

Esta propuesta, nos plantea incrementar el conocimiento presente, ampliar las posibilidades que tienen los espacios áulicos convencionales, yendo más allá de ellos, y abrirnos a un universo de posibilidades creativas e innovadoras que permitan a la Facultad de Diseño y Comunicación, expandir su estilo académico, en este caso, dentro de las fronteras del mundo virtual mediante la generación de eco sistemas digitales interrelacionados por áreas de estudio, siendo este un aporte fundamental para seguir progresando en la construcción de un modelo innovador desde nuestra universidad, para los tiempos futuros.

\section{Bibliografía sugerida}

Forte, M. \& A. Siliotti. (1997). Virtual archaeology: Great discoveries brought to life through virtual reality. Londres: Thames and Hudson.

Gibson, W. (1984). Neuromancer. Ace Science Fiction edition / The Berkley Publishing Group, New York. ISBN: 0-441-56958-7

Jones, H. (1995). Virtual reality applications. Londres: Academic Press.

McCarthy M. \& Descartes, A. (1998). Reality Architecture. Londres: Prentice-Hall.

Reggini, H. (1982). Alas para la mente. Buenos Aires: Editorial Galapago.

Rolando, F. (2005). La resignificación del espacio en la era de la virtualidad. Reflexión Académica en Diseño y Comunicación No VI. ISSN: 1668-1673. XIII Jornadas de Reflexión Académica en Diseño y Comunicación. Febrero 2005. Buenos Aires. Argentina: "Formación de Profesionales Reflexivos en Diseño y Comunicación”. Año VI, Vol. 6, Febrero 2005, Buenos Aires, Argentina. 


\begin{abstract}
This article will explore the cyberspace and how to enhance the human imagination, investigating the problem of the virtual and immersive environments and how these contribute to increasing a perceptual level of the student's in the classroom. Will analyze the limitations of the teaching strategies into the conventional classroom and reflect on the treatment of the spatial notion, contributing to develop the vision of digital ecosystem, analyzing how open an interactive and interdisciplinary window from cyberspace to the aulic environment to expand it, considering the way we access the virtual knowledge, to open ourselves to a universe of creative and innovative possibilities.
\end{abstract}

Keywords: cyberspace - perception - interaction - imagination - classroom - ecosystem creativity - innovation.

Resumo: Em tempos em que a dissolução das fronteiras entre o que foi chamado de "realidade" e a influência da virtualidade em sua construção, este trabalho explorará as delimitações, as áreas intangíveis que, do ciberespaço, aprimoram o desenvolvimento da Imaginação humana, abordando o problema de como os ambientes virtuais e imersivos podem contribuir em um nível perceptivo para o desenvolvimento dos alunos em um ambiente convencional. A abordagem analisará as limitações dos métodos de ensino em sala de aula e refletirá sobre o tratamento da noção espacial, contribuindo para desenvolver a visão do ecossistema digital, que venho investigando há algum tempo, tentando abrir uma janela interativa e interdisciplinar, que constrói uma viagem de ida e volta do ciberespaço ao ambiente aulico, para expandir a maneira como acessamos o conhecimento e nos abrimos para um universo de possibilidades criativas e inovadoras.

Palavras chave: ciberespaço - percepção - interação - imaginação - sala de aula ecossistema - criatividade - inovação.

[Las traducciones de los abstracts fueron supervisadas por el autor de cada artículo] 